\title{
Deficiency of Phosphofructo-1-kinase/Muscle Subtype in Humans Impairs Insulin Secretion and Causes Insulin Resistance
}

\author{
Michael Ristow, ${ }^{\star \S}$ Matthias Vorgerd, ${ }^{\ddagger}$ Matthias Möhlig, ${ }^{\star}$ Helmut Schatz, ${ }^{\star}$ and Andreas Pfeiffer \\ $*$ Department of Internal Medicine and ${ }^{\ddagger}$ Department of Neurology, Ruhr-University of Bochum, University Hospital Bergmannsheil, \\ D-44789 Bochum, Germany; and ${ }^{\S}$ Clinic of Internal Medicine II, University of Cologne, D-50933 Cologne, Germany
}

\begin{abstract}
Non-insulin-dependent diabetes mellitus (NIDDM) is caused by peripheral insulin resistance and impaired $\beta$ cell function. Phosphofructo-1-kinase (PFK1) is a rate-limiting enzyme in glycolysis, and its muscle subtype (PFK1-M) deficiency leads to the autosomal recessively inherited glycogenosis type VII Tarui's disease. It was evaluated whether PFK1-M deficiency leads to alterations in insulin action or secretion in humans.

A core family of four members was evaluated for PFK1-M deficiency by DNA and enzyme-activity analyses. All members underwent oral and intravenous glucose tolerance tests (oGTT and ivGTT) and an insulin-sensitivity test (IST) using octreotide.

Enzyme activity determinations in red blood cells showed that the father (46 yr, body mass index [BMI] $22.4 \mathrm{~kg} / \mathrm{m}^{2}$ ) and older son (19 yr, BMI $17.8 \mathrm{~kg} / \mathrm{m}^{2}$ ) had a homozygous, while the mother ( $47 \mathrm{yr}, \mathrm{BMI} 28.4 \mathrm{~kg} / \mathrm{m}^{2}$ ) and younger son (13 yr, BMI $16.5 \mathrm{~kg} / \mathrm{m}^{2}$ ) had a heterozygous PFK1-M deficiency. DNA analyses revealed an exon 5 missense mutation causing missplicing of one allele in all four family members, and an exon 22 frameshift mutation of the other allele of the two homozygously affected individuals. The father showed impaired glucose tolerance, and the mother showed NIDDM. By ivGTT, both parents and the older son had decreased first-phase insulin secretion and a diminished glucose disappearance rate. The IST showed marked insulin resistance in both parents and the older, homozygous son, and moderate resistance in the younger son.

PFK1-M deficiency causes impaired insulin secretion in response to glucose, demonstrating its participation in islet glucose metabolism, and peripheral insulin resistance. These combined metabolic sequelae of PFK-1 deficiency identify it as a candidate gene predisposing to NIDDM. (J. Clin. Invest. 1997. 100:2833-2841.) Key words: diabetes genetics • phosphofructokinase - glycogenosis - non-insulin-dependent diabetes mellitus • insulin secretion
\end{abstract}

Address correspondence to Prof. Dr. Andreas Pfeiffer, Medizinische Universitätsklinik Bergmannsheil, Bürkle de la Camp-Platz 1, D-44789 Bochum, Germany. Phone: 49-234-302-0; FAX: 49-234-302-64-03; E-mail: andreas.pfeiffer@ruhr-uni-bochum.de M. Ristow's current address is Clinic of Internal Medicine II, University of Cologne, D-50933 Cologne, Germany.

Received for publication 26 August 1996 and accepted in revised form 14 October 1997.

J. Clin. Invest.

(C) The American Society for Clinical Investigation, Inc. 0021-9738/97/12/2833/09 \$2.00

Volume 100, Number 11, December 1997, 2833-2841

http://www.jci.org

\section{Introduction}

Phosphofructo-1-kinase (PFK1) (1) (ATP-D-fructose-6-phosphate-1-phosphotransferase, EC 2.7.1.11) is a glycolytic enzyme converting fructose-6-phosphate to fructose-1,6-bisphosphate (1). PFK1 is known to represent a rate-limiting step in glycolysis (2). Three different isoenzymes have been described: the liver, muscle, and platelet subtypes (2). The inherited deficiency of muscle PFK1 (PFK1-M) is associated with a heterogeneous group of clinical syndromes, including hemolysis, excess glycogen storage, and exercise-induced myopathy $(3,4)$. The most common syndrome, known as glycogenosis type VII or Tarui's disease (4), appears to be prevalent among people of Ashkenazi Jewish, Italian, or Japanese ancestry with an autosomal recessive transmission (5-7).

Due to its central position in glycolysis in striated muscle and in $\beta$ cells, deficiency of PFK1 should be expected to cause the expression of a non-insulin-dependent diabetes mellitus (NIDDM) phenotype (8). The additive effects of insulin resistance of striated muscle and impaired insulin secretion of the pancreatic $\beta$ cell are thought to cause NIDDM (9-13). Striated muscle is the quantitatively predominant insulin-sensitive tissue metabolizing glucose. Since striated muscle expresses exclusively PFK1-M (2), loss of this subtype's activity should lead to peripheral insulin resistance (14). Nevertheless, Katz and co-workers (15), in contrast to their own prediction, were unable to demonstrate such a resistance in PFK1-M-deficient patients using a hyperinsulinemic euglycemic glucose clamp technique, and explained this by glucose disposal into tissues other than muscle, e.g., liver. Haller and Lewis demonstrated additionally that excess peripheral glucose depletes cells of oxidative substrates in muscle metabolism (16). Concerning insulin secretion of the pancreatic $\beta$ cell (17), a coincidence between reduced PFK1 activity and impaired insulin secretion has been described in vitro $(18,19)$, but was explained by primary phosphate depletion and consequently impaired secretion in the particular experimental setup used. Recently, Yaney and coworkers (20) demonstrated the presence of all three isotypes of PFK1 in rat-derived $\beta$ cell lines and islets at the protein level. In an extensive investigation of the complex regulation of the enzyme, negative by both ATP and citrate, and autocatalytically positive by AMP-dependent activation by fructose1,6-bisphosphate, they concluded that PFK1-M contributed most of the activity under physiological intracellular conditions. Moreover, they proposed that the autocatalytic activa-

1. Abbreviations used in this paper: BMI, body mass index; HbA1c, glycosylated hemoglobin A1c subfraction; IST, insulin-sensitivity test; ivGTT, intravenous glucose tolerance test; $K_{\mathrm{g}}$, glucose disappearance rate; NIDDM, non-insulin-dependent diabetes mellitus; oGTT, oral glucose tolerance test; PFK1, phosphofructo-1-kinase; PFK1-M, PFK1 muscle subtype; RBC, red blood cell. 
tion of PFK1-M represents the basis for the oscillatory bursting behavior of glycolysis and $\beta$ cell activity and thereby also of insulin secretion. Yaney and co-workers also speculated that PFK1-M deficiency might cause some forms of diabetes (20). The aim of this study was to evaluate a PFK1-M-deficient family as a natural knockout situation for a potentially diabetogenic mutation.

\section{Methods}

Patients. An Ashkenazi Jewish family of two parents and two sons was evaluated. Both father and the older son (son I) reported early fatigue with exercise from early childhood, whereas the mother and younger son (son II) were asymptomatic. Laboratory and physical findings, obtained by standard procedures, are listed in Table I. A detailed description of all family members was given elsewhere (21). In addition to the criteria described there, we found typical diabetic background retinopathy in the father's right eye. Son I reported an episode of insulin treatment during hepatitis A infection in 1989 for 3 mo. At that time, he was treated with steroids of unknown dosage. Thereafter, the patient did not take any drugs. The mother was diagnosed as suffering from NIDDM during this study.

To exclude a different inherited trait leading to a potential prediabetic state, the father's brother (hereafter, uncle) was evaluated additionally for a subset of criteria.

Six male controls, characterized in Table I, were evaluated.

Biochemical study of PFK1 activity in muscle biopsy. Muscle biopsies were obtained from the quadriceps muscles of the father and son I. The asymptomatic family members refused to consent to a biopsy. Biopsies, staining, and cytochemical reactions were performed as described elsewhere $(5,21-24)$.

Biochemical study of PFK1 activity in erythrocytes. The PFK1 activity in red blood cells (RBC) was determined in all family members as described elsewhere (21) according to the criteria of the International Committee for Standardization in Hematology (25).

Genetic analysis of PFK1 genomic DNA. Genomic DNA was extracted from blood with the QIamp blood kit (QIAGEN GmbH, Hilden, Germany). Mutation analyses were performed by PCR amplification and either subsequent dideoxy chain termination sequencing (26) (exon 5) or restriction analyses (exon 22). The PCR fragments analyzed here were obtained with two primer pairs: for exon 5 , upstream 5'gTgTCACACAgggTTATCA and downstream 5'ggACAggAgTTCTCTggA; for exon 22, upstream 5'gTTTCTTTCTCCA-
gggTg and downstream 5'CCATTACggTAACTCTCTTT. PCR was performed as described elsewhere (27). Restriction analyses were done according to standard procedures (26) with the enzyme BanII from Boehringer Mannheim (Mannheim, Germany).

Oral glucose tolerance test (oGTT). oGTTs were performed after $3 \mathrm{~d}$ of carbohydrate-rich meals. After a 12-h overnight fast, the patients ingested $75 \mathrm{~g}$ of solubilized glucose, and sampling of capillary blood for blood glucose and venous blood for insulin and C-peptide was performed at $0,30,60,90,120,150$, and $180 \mathrm{~min}$.

Intravenous glucose tolerance test (ivGTT). For ivGTTs, $0.33 \mathrm{~g}$ glucose $/ \mathrm{kg}$ body wt was injected intravenously as a $40 \%$ solution into the right antecubital vein within $2 \mathrm{~min}$. Blood for insulin and C-peptide was drawn from a permanent cannula placed into the left radial vein while keeping the hand in a water bath at $44^{\circ} \mathrm{C}$, to obtain arterialized blood as suggested elsewhere (28). Samples were drawn at 0,1 , $2,3,4,5,6,8,10,20,40$, and $60 \mathrm{~min}$. The glucose disappearance rate $\left(K_{\mathrm{g}}\right)$ was calculated using the following formula, with $\operatorname{Ln}$ logarithm (29):

$\frac{100 \times \operatorname{Ln} 2}{t_{1 / 2}}$ [percent per minute].

Insulin-sensitivity test (IST). To determine insulin resistance, the IST established by Reaven and co-workers (30) was performed by parallel intravenous infusion of glucose $(9 \mathrm{mg} / \mathrm{kg} \cdot \mathrm{min})$, insulin $(2$ $\mathrm{mIU} / \mathrm{kg} \cdot \mathrm{min})$, and octreotide $(0.5 \mu \mathrm{g} / \mathrm{min})(31)$, and then sampling of capillary blood for blood glucose and venous blood for insulin and C-peptide at $0,30,60,90,120,150,160,170$, and 180 min after preparation, as for the oGTT. The IST has been demonstrated to be highly correlated with the results of the hyperinsulinemic euglycemic clamp (32) ( $r=0.93$ [30] and $r=0.91$ [33], respectively). Since octreotide has been described to decrease liver glycolysis (34), we preferred this test due to methodological problems with the clamp as given above (15), and our experience with son I confirming absence of insulin resistance. In this test, insulin resistance correlates with the difference in the blood glucose rise, from baseline to steady state (mean of four measurements at 150,160,170, and $180 \mathrm{~min}$ ), during infusion.

Euglycemic hyperinsulinemic clamp. Insulin resistance was also determined by euglycemic hyperinsulinemic clamps as described ( 30 , 32). The insulin infusion rate was $60 \mathrm{mIU} / \mathrm{kg} \cdot \mathrm{h}$, and glucose was clamped at $90 \mathrm{mg} / \mathrm{dl}(4.9 \mathrm{mmol} / \mathrm{liter})$. Six healthy controls matched for age and weight.

Assay conditions. Glucose was determined with a glucose analyzer (model 2; Beckman Instruments $\mathrm{GmbH}$, Munich, Germany) and reagent kit (Beckman Instruments $\mathrm{GmbH}$ ); insulin was determined by the Coat-a-count insulin kit (Diagnostic Products Corp., Cologne, Germany), and C-peptide was determined by C-peptide

Table I. Genotype and Parameters Concerning Glucose Metabolism of Five Family Members and Six Male Controls

\begin{tabular}{|c|c|c|c|c|c|c|}
\hline & Father & Mother & Son I & Son II & Uncle & Controls (SD) \\
\hline Age (yr) & 46 & 47 & 19 & 12 & 57 & $21.1(2.78)$ \\
\hline BMI $\left(\mathrm{kg} / \mathrm{m}^{2}\right)$ & 22.4 & 28.4 & 17.8 & 16.5 & 24.2 & $19.8(3.1)$ \\
\hline $\mathrm{PFK}$ in RBCs $(\mu \mathrm{mol} / \mathrm{min} \cdot \mathrm{g})$ & 3.3 & 4.2 & 2.9 & 4.2 & 4.0 & $6.0(0.1)$ \\
\hline PFK histochemical stain & Neg. & ND & Neg. & ND & ND & ND \\
\hline Exon/intron 5 mutation & $\mathrm{G} \rightarrow \mathrm{A}$ & $\mathrm{G} \rightarrow \mathrm{A}$ & $\mathrm{G} \rightarrow \mathrm{A}$ & $\mathrm{G} \rightarrow \mathrm{A}$ & $\mathrm{G} \rightarrow \mathrm{A}$ & $\mathrm{G}$ \\
\hline Exon 22 deletion & $\mathrm{C}$ & No & $\mathrm{C}$ & No & No & No \\
\hline $\operatorname{HbA} 1 \mathrm{c}(\%)^{*}$ & 4.4 & 6.9 & 4.2 & 5.4 & 5.0 & $4.8(0.24)$ \\
\hline Fructosamine $(\mu \mathrm{mol} / \text { liter })^{*}$ & 277 & 332 & 256 & 247 & 251 & $242(9.5)$ \\
\hline Fasting insulin (mIU/liter) & $15 / 17$ & $7 / 5$ & $14 / 20$ & $8 / 9$ & 10 & $7(3.5)$ \\
\hline Fasting proinsulin (pmol/liter) & 56 & 16 & 32 & 28 & 30 & $14.7(6.8)$ \\
\hline Fasting glucose (mmol/liter) (SD) & $5.9(0.12)$ & $5.3(0.36)$ & $5.4(0.17)$ & $4.6(0.09)$ & 5.0 & $4.8(0.24)$ \\
\hline$K_{\mathrm{g}}(\% / \mathrm{min})$ & 0.98 & 0.60 & 1.26 & 1.39 & ND & $1.81(0.28)$ \\
\hline Diabetic retinopathy & Yes & No & No & No & No & No \\
\hline
\end{tabular}

$*$ Normal range for fructosamine $=220-270 \mu \mathrm{mol} / \mathrm{liter}$ and for HbA1c $=4-6 \%$. Neg, Negative. ND, not done. 
RIA (Diagnostic Products Corp.), both using a gamma counter (Gamma C12; Diagnostic Products Corp.).

\section{Results}

Since a detailed description of the family has been published (21), only a summarizing list of results is given in Table I. Concerning the PFK1 phenotype that refers to total PFK1-enzyme activity, father and son I showed $\sim 50 \%$ (55 and 48\%, respectively) reduction of total PFK1 activity in RBCs, while the remaining three family members had an $\sim 25 \%$ reduction (Table I). Since $50 \%$ of total PFK1 activity in RBCs is contributed by the muscle subtype (25) in healthy controls, these results are compatible with complete and 50\% reduction of PFK1-M, respectively. Genotyping by DNA analysis reflected these results and revealed a compound heterozygous (pseudodominant) inheritance. All family members showed $G$ to A point mutation at the first nucleotide of intron 5, changing the invariant GT of the splice donor site to AT, and leading to exon 5 deletion by missplicing (Fig. 1). Father and son I additionally had a single base deletion of the nucleotide 2003 within exon 22 , resulting in a frameshift leading to a stop codon 47 nucleotides downstream. This predicted the generation of a truncated PFK1-M protein with 16 altered amino acids at the carboxy terminus. The deletion alters a BanII restriction site in exon 22, leading to complete restriction of the patients carrying two wild-type alleles, and an RFLP of $81 \mathrm{bp}$ in the father and son I carrying the heterozygous mutation for this deletion (Fig. 2).

All family members were negative for insulin antibodies, islet cell antibodies, and glutamic acid decarboxylase II antibodies, excluding an immunological reason for altered glucose metabolism. Glycosylated hemoglobin A1 c subfraction (HbA1c) is a long-term parameter for average blood glucose levels which is based on time-dependent nonenzymatic glycation of hemoglobin. HbA1c was elevated in the heterozygous diabetic mother, but normal in all remaining family members (Table I).

\section{Ban II - site: GpuGCpyC wild-type: GGGAGCCCAACCCC mutated: GGGAGCC AACCCC}

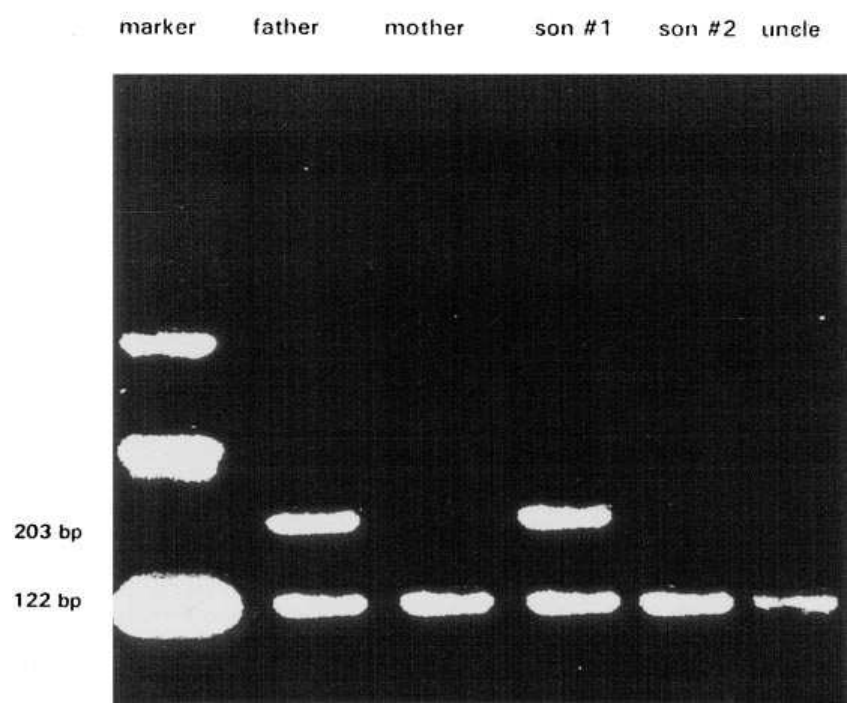

Figure 2. PCR-based RFLP of PFK1-M exon 22 showing a heterozygous mutation of the BanII restriction site in the father and son I.

However, father and son I are known to suffer from persistent hemolysis typical of PFK1-M deficiency $(5,6)$, and HbA1c is decreased by hemolysis (35) due to shortened half-life of RBCs. Therefore, fructosamine representing an intermediateterm parameter for average blood glucose levels independent of RBC half-life was determined. A pathological increase was observed in the mother and, less markedly, in the father, whereas the uncle and both sons were in the normal range.

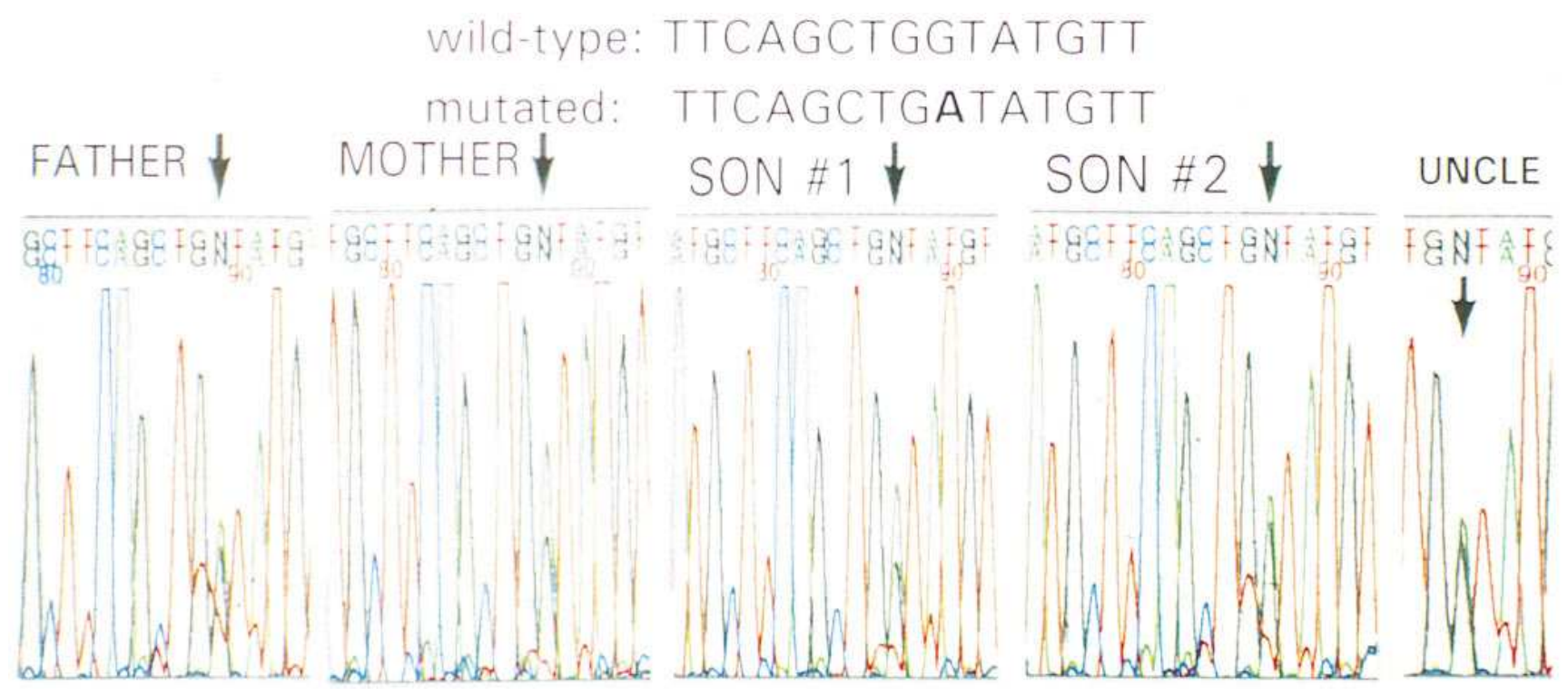

Figure 1. Dideoxy chain-termination sequencing of PFK1-M exon/intron 5 showing a heterozygous G (black) to A (green) exchange in all family members. Arrow, Signal overlap. 


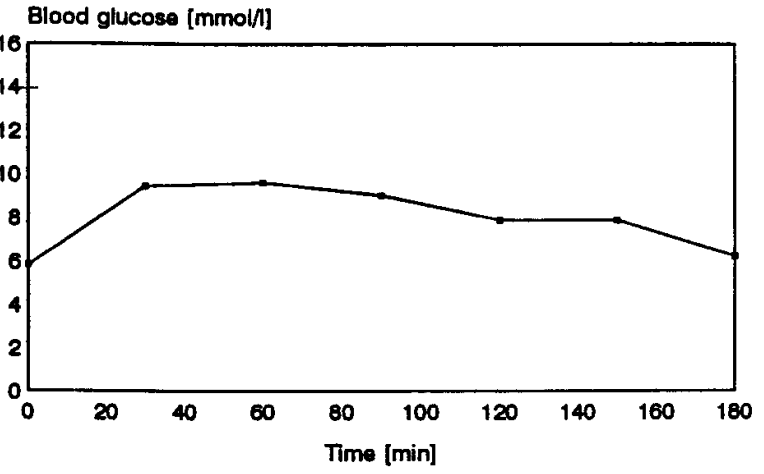

oGTT / son I

100 vs. $75 \mathrm{~g}$ load

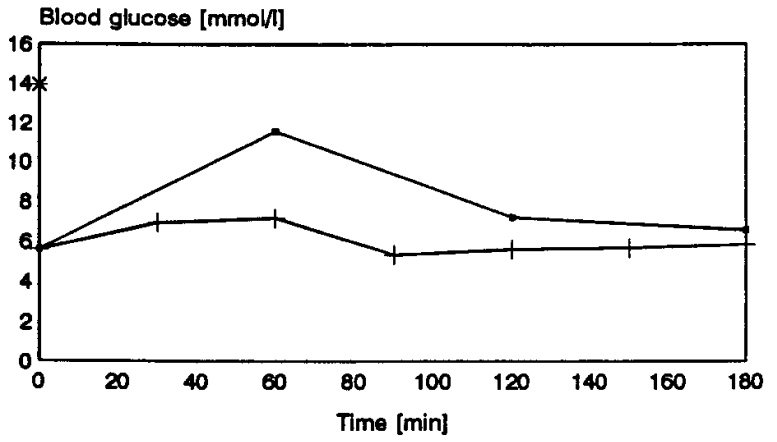

OGTT / controls

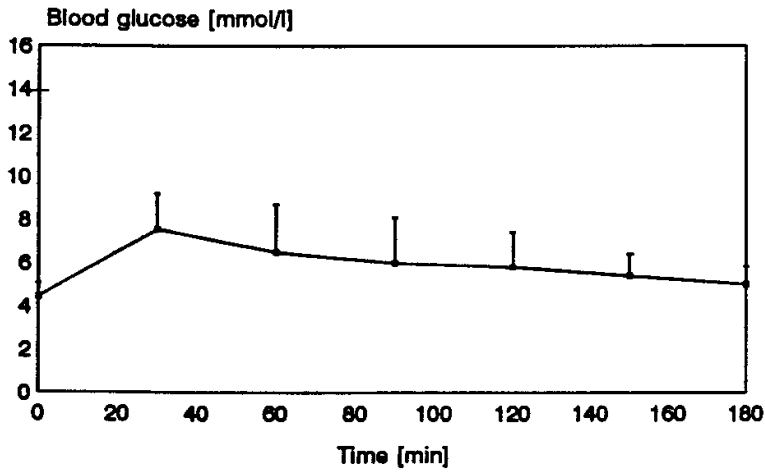

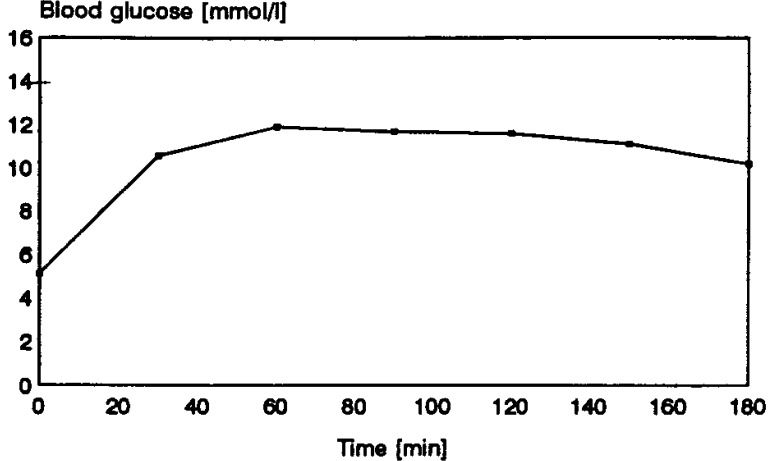

oGTT / son II

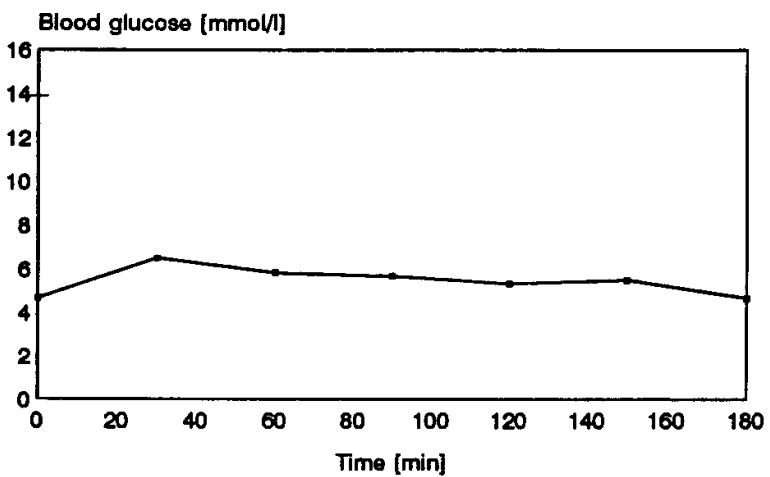

oGTT / uncle

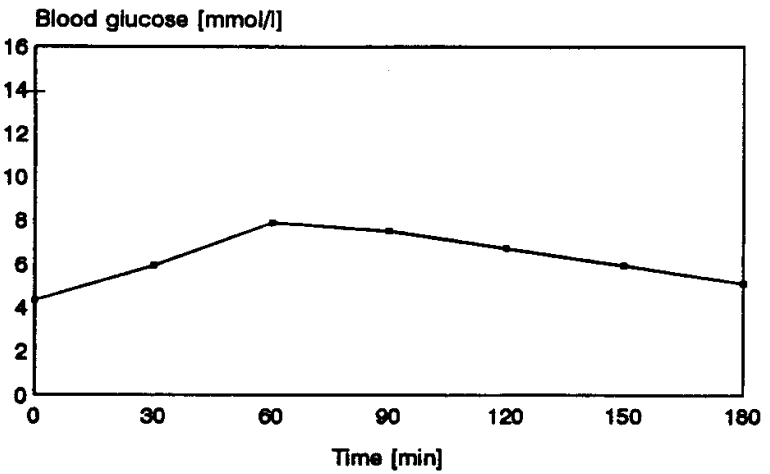

Figure 3. Capillary blood glucose response to a 75 -g oral glucose challenge.

Fasting insulin (determined twice on different days) and proinsulin levels were elevated in both father and son I. Fasting blood glucose (determined three times on different days) was elevated slightly to $5.9 \mathrm{mmol} /$ liter only in the father, and was in the upper-normal range in the (diabetic) mother and son I. oGTTs were performed to determine whether NIDDM, according to World Health Organization criteria, was present.

Results of oGTTs showed normal profiles for the uncle and both sons, impaired glucose tolerance for the father, and dia- betes for the mother (Fig. 3). Fig. 3 additionally shows results of an oGTT of son I using a 100-g glucose load, demonstrating an impaired response to this challenge. ivGTTs have been established to provide a sensitive index of $\beta$ cell function, particularly with regard to the rapid first-phase insulin response (28). Therefore, results of ivGTTs were evaluated for insulin secretion, especially the first-phase peak, and glucose elimination. The first-phase insulin peak was missing completely in both father and mother, reduced significantly $(<50 \%$ of the 


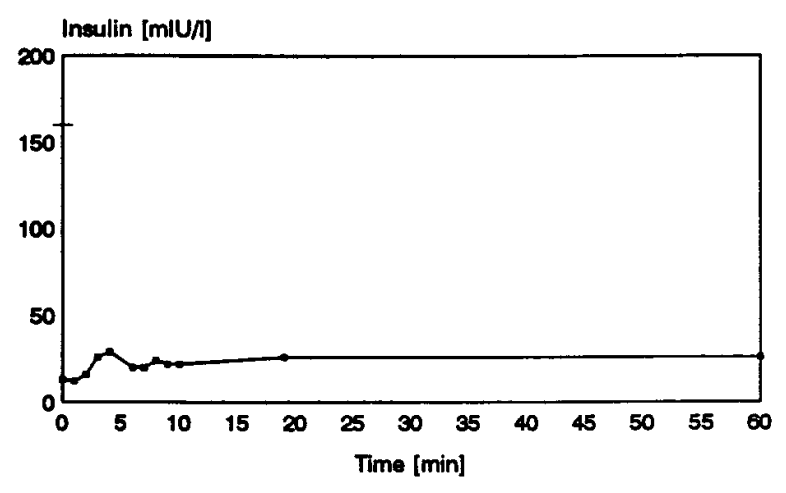

ivGTT / son I

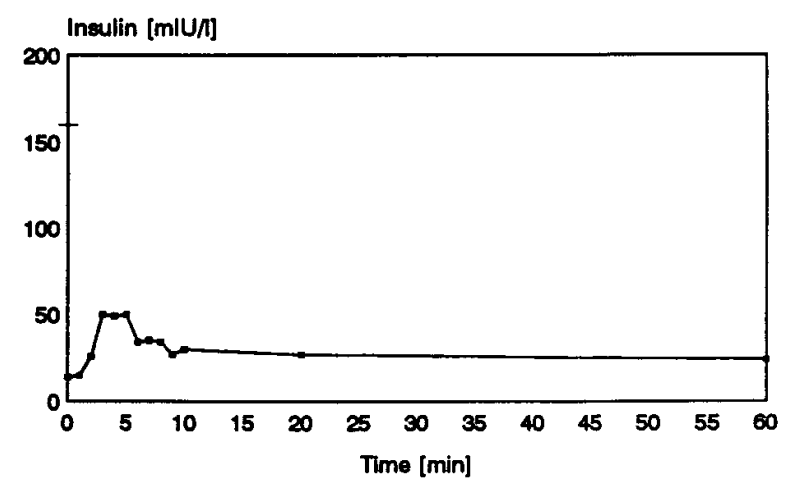

ivGTT / controls

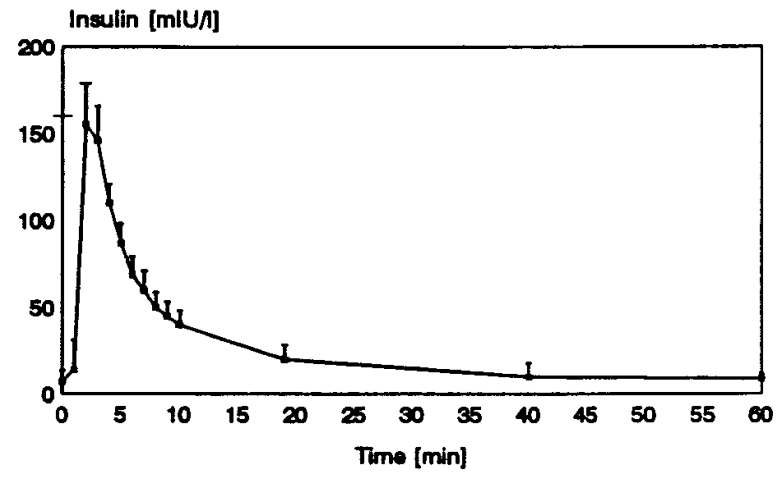

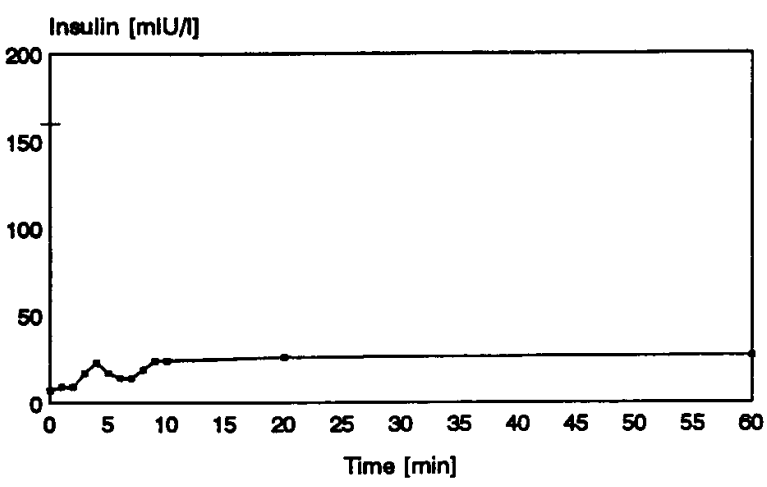

ivGTT / son II

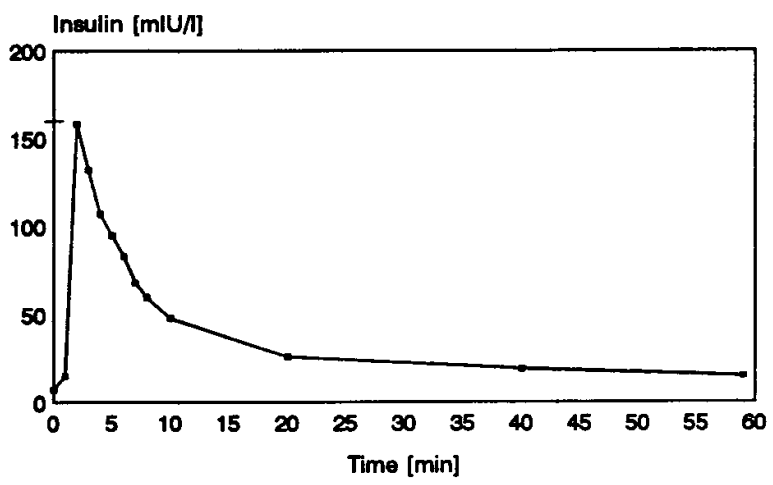

Figure 4. Insulin response to intravenous glucose challenge $(0.33 \mathrm{~g} / \mathrm{kg})$.

controls) in son I, and normal in son II (Fig. 4). The glucose disappearance rate $\left(K_{\mathrm{g}}\right)$ was decreased in all family members (Fig. 5, and Table I). A previous study had evaluated insulin resistance in PFK1-M-deficient patients using euglycemic hyperinsulinemic clamps. Unexpectedly, this study did not reveal insulin resistance (15). Therefore, we wondered whether the euglycemic hyperinsulinemic clamp would confirm this result. We tested son I, who did not have other possible causes of insulin resistance, such as elevated blood glucose or increased body mass index (BMI). Indeed, glucose infusion rates remained in the normal range $(6.0 \mathrm{mg} / \mathrm{kg} \cdot \mathrm{min}$ in son I compared with $6.2 \pm 0.9 \mathrm{mg} / \mathrm{kg} \cdot \mathrm{min}$ in three lean controls), thus confirming the results of Katz and co-workers (15). One explanation for this unexpected finding was that a high glucose uptake by the liver might compensate for decreased glucose uptake by the muscle. Therefore, we used a different technique to determine insulin resistance, and performed an IST with octreotide, which appears to inhibit glucose uptake by the liver (34).

Indeed, the results of octreotide IST showed a reduced insulin sensitivity in all family members tested which was pronounced in mother, father, and son I, and moderate in son II (Fig. 6). To control for the complete suppression of endoge- 


\section{ivGTT / father}

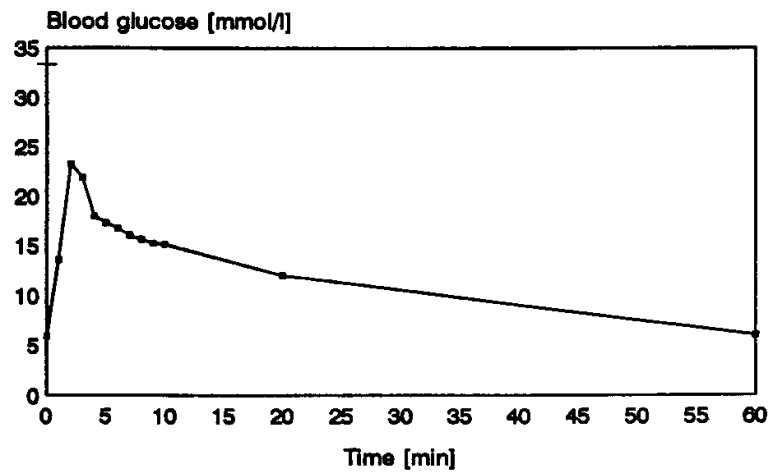

ivGTT / son I

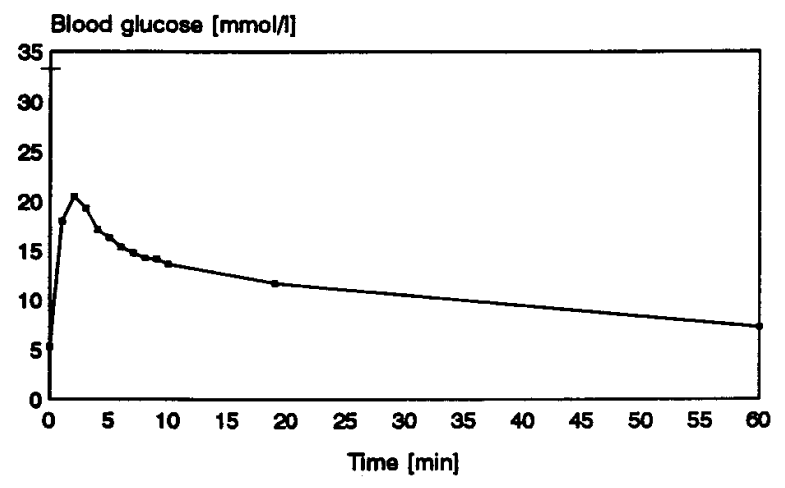

ivGTT / controls

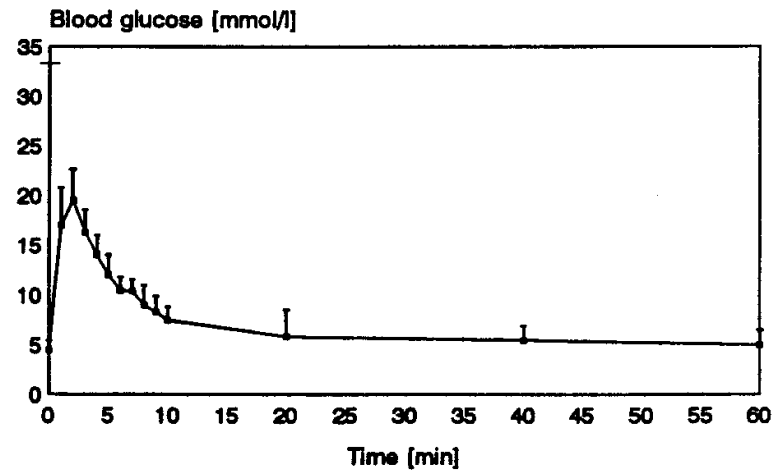

ivGTT / mother

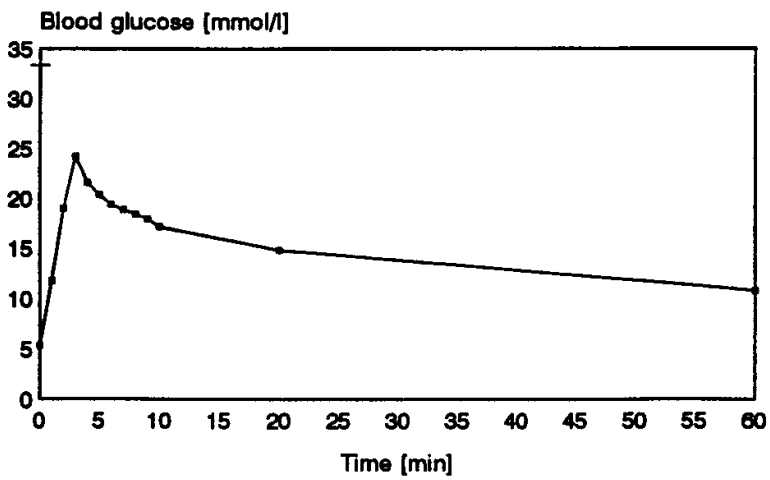

ivGTT / son II

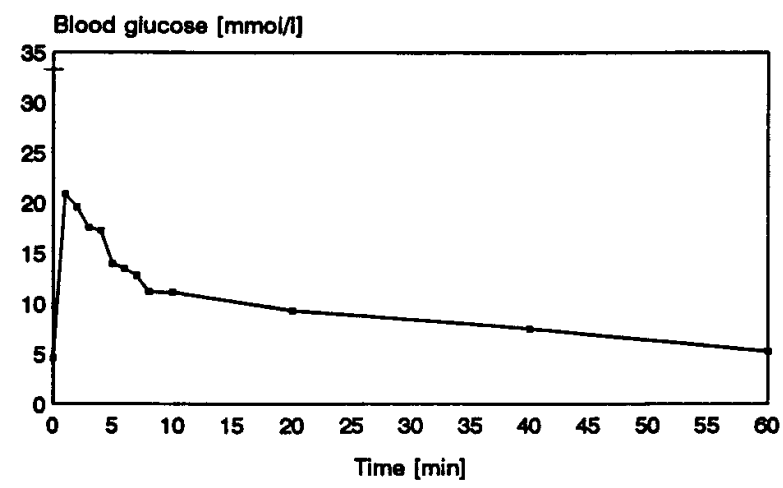

Figure 5. Capillary blood glucose response to intravenous glucose challenge $(0.33 \mathrm{~g} / \mathrm{kg})$.

nous insulin secretion, we measured C-peptide, which remained as low as the fasting value in all four subjects throughout the test (data not shown).

\section{Discussion}

The pathogenesis of NIDDM involves a combination of peripheral insulin resistance and impaired $\beta$ cell function (9-13). Very little is known about the hereditary factors leading to a persistent prediabetic state, which in combination with additional genetic or environmental factors leads to development of NIDDM in later periods of life. Recently, some diabetic states were shown to be associated with certain mutations at the DNA level (36-44). One of these defects might concern a rate-limiting enzyme, e.g., in muscle glycolysis or in $\beta$ cell insulin secretion. Glucokinase as the most promising candidate for this role has been excluded for the majority of NIDDM patients, but was shown to cause a mild dominantly inherited form of NIDDM (38). Therefore, evaluating this PFK1-M-deficient family offers a chance to study its possible role in predisposing to NIDDM in humans $(45,46)$. Insulin resistance might be expected in PFK1-M deficiency due to the fact that glucose 
Blood glucose [mmol/l]

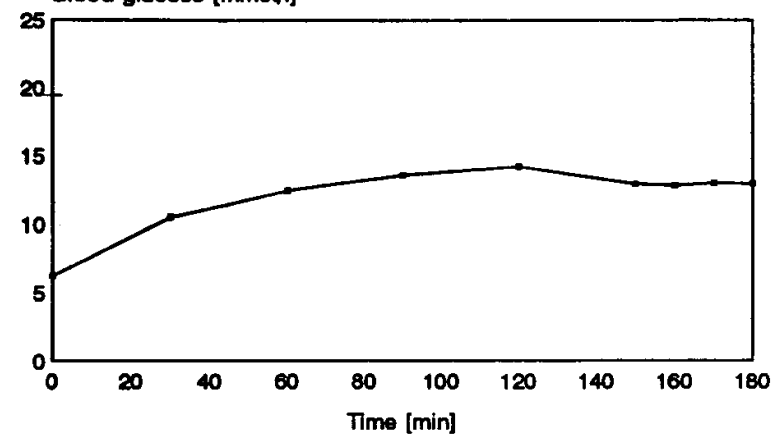

IST / son I

Blood glucose [mmol/]]

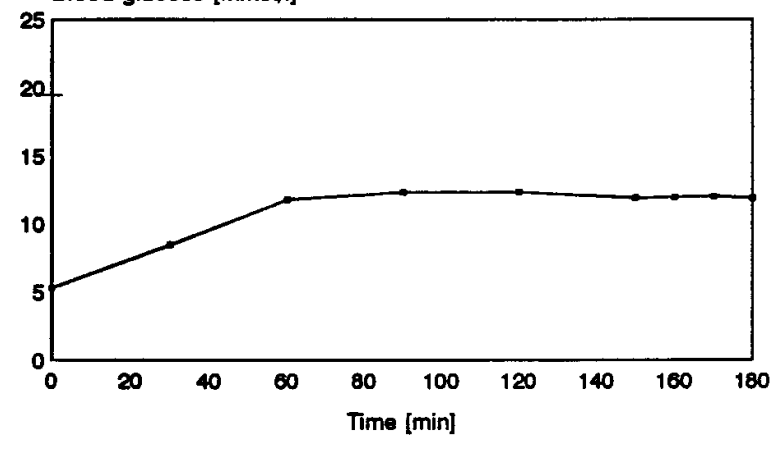

IST / controls

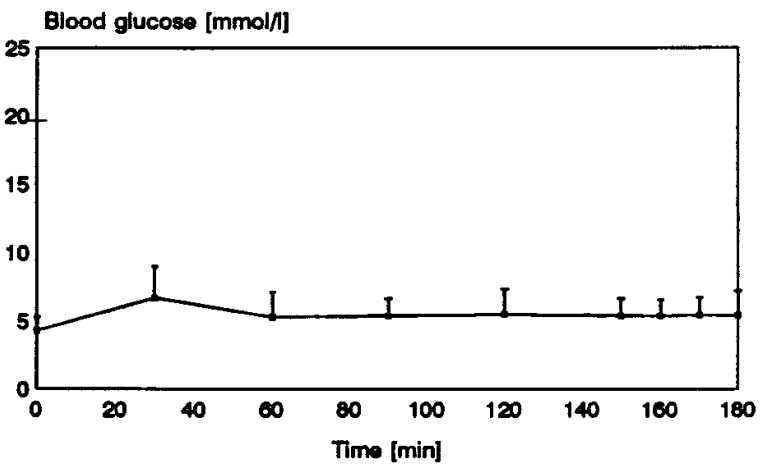

Blood glucose [mmol//]

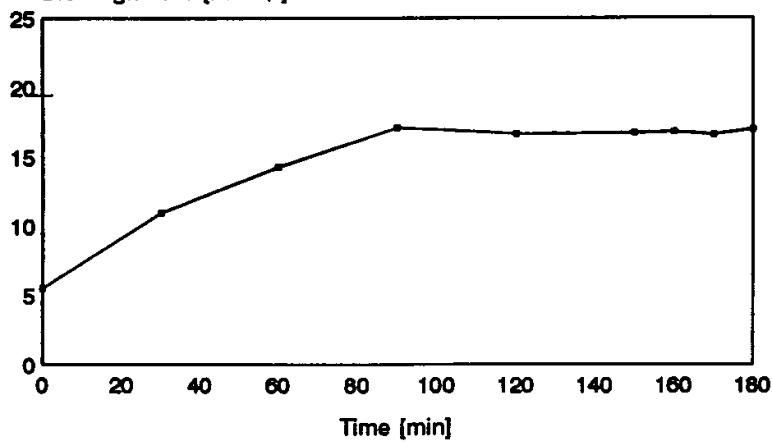

IST / son II

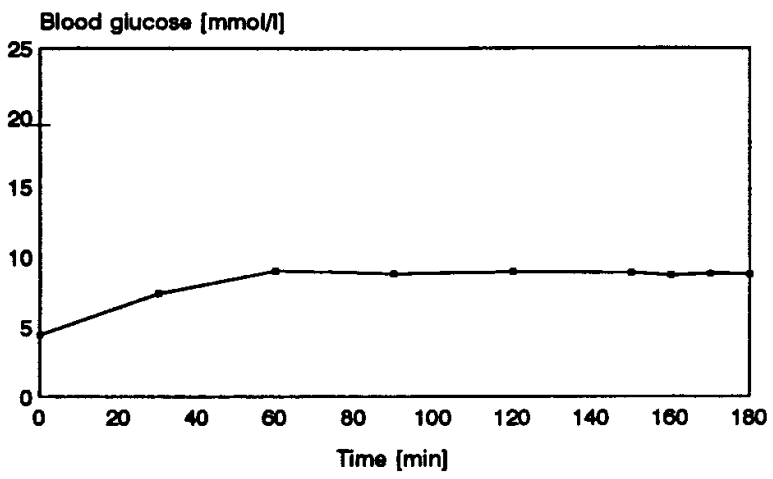

Figure 6. Insulin sensitivity measured as capillary blood glucose response to parallel infusion of insulin, glucose, and octreotide as described in Methods.

disposal into striated muscle should be diminished markedly, since PFK1-M is the only subtype in striated muscle, and the rate-limiting step in glycolysis in this tissue. Impaired $\beta$ cell function, detectable as a loss of first-phase insulin secretion, should also be expected, due to delayed metabolic glucose sensing of the $\beta$ cell. Although the $\beta$ cell expresses all three PFK1 subtypes, loss of the predominant PFK1-M activity should lead to decreased ATP production and ATP/ADP ratio due to decreased glucose metabolism. As a consequence, inadequate activation of the ATP-dependent $\mathrm{K}^{+}$-channel, diminished $\mathrm{Ca}^{2+}$-influx, and reduced early insulin exocytosis might be expected (47). In parallel, a decreased ATP/ADP ratio might upregulate the remaining subtypes of PFK1 (20), and thereby increase glucose metabolism via the pentose phosphate shunt as a time- and ATP-consuming pathway. Nevertheless, both mechanisms clearly should not rescue loss of PFK1-M activity in vivo, since otherwise, excess glycogen storage was not present in affected patients, and excess glycogen storage is the characteristic feature of Tarui's disease.

The family evaluated in this study consists of three heterozygously PFK1-M-deficient, asymptomatic members (mother, uncle, and son II) and two homozygously affected, symptom- 
atic members (father and son I), as shown by DNA analysis. Enzyme assays performed in RBCs confirmed these results (Table I, and Figs. 1 and 2).

oGTTs revealed impaired glucose tolerance in the father and diabetes in the mother (Fig. 3). The uncle, although older than the father (his brother), showed a normal oGTT. This fact supports the view that an independently inherited trait other than PFK1-M deficiency leading to NIDDM is unlikely. The diabetic oGTT of the mother cannot be attributed unambiguously to her heterozygous PFK1-M deficiency, since (a) a different inherited trait could not be excluded in the mother's family, and (b) the uncle (her brother-in-law), with a similar enzymatic status but leaner, was shown to react normally to the oral glucose challenge (Fig. 3).

As theoretically expected, all four patients showed insulin resistance compared with the control group in the octreotide IST (Fig. 6). This could not be shown by previous studies (15) using euglycemic hyperinsulinemic clamps, a finding we reproduced in this study with the homozygous son I. The father and the older son I, both homozygously PFK1-M-deficient, showed a higher degree of resistance in the octreotide IST than the younger heterozygous son II. The mother, although heterozygous, showed the highest degree of insulin resistance, which might be explained by the additive effects of heterozygous PFK1-M deficiency, age, and obesity. Whereas the hyperinsulinemic euglycemic clamp failed to detect insulin resistance in the homozygously PFK1-M-deficient son I, probably due to compensatory glucose disposal into tissues other than muscle (15), the measurement by IST used here revealed a good correlation between degree of PFK1-M activity and insulin resistance (Fig. 6). As suggested earlier, the advantage of the octreotide IST in this setting is possibly due to efficient inhibition of liver glycolysis by octreotide (34), which may be misleading in hyperinsulinemic euglycemic clamps. Insulin resistance should not be expected in the liver, which expresses the unaffected PFK liver subtype.

Evaluating the insulin secretion of the pancreatic $\beta$ cell, the ivGTT revealed a loss of first-phase insulin secretion in both parents, as well as a significant reduction (48) in the older son I. The loss of first-phase insulin secretion in son I provides compelling evidence for an important role for PFK1-M in $\beta$ cell glucose metabolism, because son I did not have significant fasting hyperglycemia and was not insulin resistant in the absence of octreotide, which excludes other known causes of impaired first-phase insulin secretion (49). The first phase in the heterozygous younger son II might remain normal, due to the fact that $(a)$ in contrast to other tissues, including muscle, glucokinase is the primary rate-limiting step of glucose metabolism within the $\beta$ cell (8), and (b) the activity of PFK1-M in his $\beta$ cell $(20,50)$ is diminished by $50 \%$, which appears to be sufficient for near normal glucose metabolism, at least at his age and BMI. The normal first-phase insulin secretion in the heterozygous son also supports the absence of further hereditary defects in insulin secretion in this family. Therefore, the reduction in the first phase of insulin secretion must be interpreted, at least in the older son I, as a direct consequence of loss of PFK1-M activity in the $\beta$ cell. The more pronounced reduction in the father's first phase in vivo may involve factors in addition to the loss of PFK1-M activity. A fasting blood glucose $>6.4 \mathrm{mmol} /$ liter has been associated with loss of first-phase insulin secretion (49) due to glucose toxicity (51). The father's fasting blood glucose was $5.9 \mathrm{mmol} /$ liter and, thus, below this threshold, which, however, might play some role. Additionally, insulin resistance increases with age thereby aggravating the resistance due to PFK1-M deficiency, and first-phase insulin secretion declines with age. The father also showed impaired glucose tolerance and elevated fasting insulin and proinsulin levels (50-52). Although these arguments might explain decreased first-phase insulin secretion in the father, its complete loss is not well-explained by these secondary causes, and PFK1-M deficiency is very likely to contribute to this loss.

The data of this study support the proposal of Yaney and co-workers (20) that the PFK1-M subtype of PFK plays a predominant role in $\beta$ cell function, although both other isoforms, PFK1-C and PFK1-L were present in $\beta$ cells. The phenotype observed, i.e., lack of first-phase insulin secretion, may indicate that the $\beta$ cell bursting activity proposed to result from PFK1-M autocatalytic activation by its product may be required for rapid maximal insulin secretion.

In conclusion, homozygous PFK1-M deficiency seems to lead to a phenotype strongly predisposing to NIDDM. Even though this may escape detection in adolescents by screening tests (son I, Fig. 3, and reference 15), it may cause impaired glucose tolerance, and may facilitate the development of late complications of clinical relevance typical for NIDDM in midlife, as suggested by the retinopathy seen in the father. Since the prevalence of clinically apparent PFK1-M deficiency is low (homozygous, 1 in 100,000; heterozygous, $0.7 \%$ in the general population) and restricted mainly to certain ethnic groups (53), association studies based on PFK1-enzyme activity measurements in RBCs and subsequent DNA analyses in NIDDM patients will have to elucidate whether these alterations may account for a subgroup of type II diabetes patients.

\section{Acknowledgments}

We would like to thank the members of the subject family for their kind cooperation; Dr. M. Krieg and Dr. M. von Tettau for standard laboratory analyses; G. Blome, S. Ritter, and C. Wolff for excellent technical assistance; Dr. M. Nauck for help with hyperinsulinemic euglycemic clamps; Dr. W. Mallaisse, Dr. D. Müller-Wieland, Dr. W. Krone, Dr. J.P. Malin, Dr. B. Knebel, Dr. J. Kotzka, Dr. J. MüllerBerghaus, and the two anonymous reviewers for critical reading of the manuscript and for helpful suggestions.

M. Ristow is supported by the German Diabetes Association (Deutsche Diabetes Gesellschaft), and M. Vorgerd by the German Association for Muscle Diseases (Deutsche Gesellschaft für Muskelkranke). E. van Schaftingen is supported by the Belgium National Fund for Scientific Research. A. Pfeiffer is supported by the Hermann and Lilly Schilling Stiftung.

\section{References}

1. Goldhammer, A.R., and H.H. Paradies. 1979. Phosphofructokinase: structure and function. Curr. Top. Cell. Regul. 15:109-141.

2. Dunaway, G..A., T.P. Kesten, T. Sebo, and R. Trapp. 1988. Analysis of the phosphofructokinase subunits and isoenzymes in human tissues. Biochem. J. 251:677-683.

3. Vora, S., M. Davidson, C. Seaman, A.F. Miranda, N.A. Noble, K.R. Tanaka, E.P. Frenkel, and S. DiMauro. 1983. Heterogeneity of the molecular lesions in inherited phosphofructokinase deficiency. J. Clin. Invest. 72:19952006.

4. Tarui, S., G. Okuno, and Y. Ikura. 1965. Phosphofructokinase deficiency in skeletal muscle. A new type of glycogenosis. Biochem. Biophys. Res. Commun. 19:517-523.

5. Layzer, R.B., L.P. Rowland, and H.M. Ranney. 1967. Muscle phosphofructokinase deficiency. Arch. Neurol. 17:512-523.

6. DiMauro, S., and S. Tsujino. 1994. Nonlysosomal glycogenoses. In Myology. A.G. Engel and B.Q. Banker, editors. McGraw-Hill Inc., New York. 1554- 
1576.

7. Sherman, J.B., N. Raben, C. Nicastri, Z. Argov, H. Nakajima, E.M. Adams, C.M. Eng, T.M. Cowan, and P.H. Plotz. 1994. Common mutation in the phosphofructokinase-M gene in Ashkenazi Jewish patients with glycogenosis VII - and their population frequency. Am. J. Hum. Genet. 55:305-313.

8. Randle, P.J. 1993. Glucokinase and candidate genes for type II (non-insulin dependent) diabetes mellitus. Diabetologia. 36:269-275.

9. DeFronzo, R.A., R.C. Bonadonna, and E. Ferrannini. 1992. Pathogenesis of NIDDM: a balanced overview. Diabetes Care. 15:318-368.

10. Kahn, C.R. 1994. Insulin action, diabetogenes, and the cause of type II diabetes. Diabetes. 43:1066-1084.

11. Groop, L.C., E. Widen, and E. Ferrannini. 1993. Insulin resistance and insulin deficiency in the pathogenesis of type 2 (non-insulin-dependent) diabetes mellitus: errors of metabolism or methods? Diabetologia. 36:1326-1331.

12. Taylor, S.I., D. Accili, and Y. Imai. 1994. Insulin resistance or insulin deficiency. Which is the primary cause of NIDDM? Diabetes. 43:735-740.

13. Hales, C.N. 1994. The pathogenesis of NIDDM. Diabetologia. 37(Suppl. 2):S162-S168.

14. van Schaftingen, E. 1993. Glycolysis revisited. Diabetologia. 36:581-588.

15. Katz, A., M.K. Spencer, S. Lillioja, Z. Yan, D.M. Mott, R.G. Haller, and S.F. Lewis. 1991. Basal and insulin-mediated carbohydrate metabolism in human muscle deficient in phosphofructokinase 1. Am. J. Physiol. 261(Endocrinol. Metab. 24):E473-E478.

16. Haller, R.G., and S.F. Lewis. 1991. Glucose-induced exertional fatigue in muscle phosphofructokinase deficiency. N. Engl. J. Med. 324:364-369.

17. Malaisse, W.J., F. Malaisse-Lagae, A. Sener, E. van Schaftingen, and H.G. Hers. 1981. Is the glucose-induced stimulation of glycolysis in pancreatic islets attributable to activation of phosphofructokinase by fructose 2,6-bisphosphate? FEBS (Fed. Eur. Biochem. Soc.) Lett. 125:217-219.

18. Perna, A.F., G.Z. Fadda, and S.G. Massry. 1991. Inhibition of phosphofructokinase activity in pancreatic islets in phosphate depletion. Miner. Electrolyte Metab. 17:8-11.

19. Zhou, X.J., G.Z. Fadda, A.F. Perna, and S.G. Massry. 1991. Phosphate depletion impairs insulin secretion by pancreatic islets. Kidney Int. 39:120-128.

20. Yaney, G.C., V. Schultz, B.A. Cunningham, G.A. Dunaway, B.E. Corkey, and K.A. Tornheim. 1995. Phosphofructokinase isoenzymes in pancreatic islets and clonal $\beta$ cells (INS-1). Diabetes. 44:1285-1289.

21. Vorgerd, M., M. Ristow, E. van Schaftingen, M. Tegenthoff, F. Jerusalem, and J.P. Malin. 1996. Muscle phosphofructokinase deficiency in two generations. J. Neurol. Sci. 141:95-99.

22. Bonilla, E., and D.L. Schotland. 1970. Histochemical diagnosis of muscle phosphofructokinase deficiency. Arch. Neurol. 22:8-12.

23. Dubowitz, V. 1985. Muscle Biopsy: A Practical Approach. Bailliere Tindall Ltd., London.

24. DiMauro, S., C. Angelini, and C. Catani. 1967. Enzymes of the glycogen cycle and glycolysis in various human neuromuscular disorders. J. Neurol. Neurosurg. Psychiatry. 30:411-415.

25. Beutler, E., K.G. Blume, J.C. Kaplan, G.W. Löhr, B. Ramot, and W.N. Valentine. 1977. International Committee for Standardization in Haematology: recommended methods for red-cell enzyme analysis. Br. J. Haematol. 35:331-340.

26. Ausubel, F.M. 1993. Current Protocols in Molecular Biology. Harvard University Press, New York.

27. Ristow, M., M. Möhlig, M. Rifai, H. Schatz, K. Feldmann, and A. Pfeiffer. 1995. New isoniazid/ethionamide resistance gene mutation and screening for multidrug-resistant Mycobacterium tuberculosis strains. Lancet. 346:502-503.

28. Rayman, G., P. Clark, A.E. Schneider, and C.N. Hales. 1990. The first phase insulin response to intravenous glucose is highly reproducible. Diabetologia. 33:631-634.

29. Kruse-Jarres, J.D. 1979. Blutglucose-Biokinetik. Georg Thieme Verlag, Stuttgart, Germany. 72-74

30. Pei, D., C.N.O. Jones, R. Bhargava, Y.D.I. Chen, and G.M. Reaven. 1994. Evaluation of octreotide to assess insulin-mediated glucose by the insulin suppression test. Diabetologia. 37:843-845.

31. Bauer, W., U. Briner, W. Doepfner, R. Haller, R. Huguenin, P. Marbach, T.J. Petcher, and J. Pless. 1982. SMS 201-995: a very potent and selective octapeptide analogue of somatostatin with prolonged action. Life Sci. 31:11331140.

32. Greenfield, M.S., L. Doberne, F. Kraemer, T. Tobey, and G.M. Reaven. 1981. Assessment of insulin resistance with the insulin suppression test and the euglycemic clamp. Diabetes. 30:387-392.

33. Mimura, A., S. Kageyama, M. Maruyama, Y. Ikeda, and Y. Isogai. 1994 Insulin sensitivity test using a somatostatin analogue, octreotide. Horm. Metab. Res. 26:184-187.

34. Bartlett, D.L., S.L. Charland, and M.H. Torosian. 1995. Reversal of tumor-associated hyperglucagonemia as treatment for cancer cachexia. Surgery (St. Louis). 118:87-97.

35. Baule, G.M., D. Onorato, G. Tola, G. Forteloni, and T. Meloni. 1983 Hemoglobin A1 in subjects with G-6-PD deficiency during and after hemolytic crises due to favism. Acta Haematol. (Basel). 69:15-18.

36. van den Ouweland, J.M.W., H.H. Lemkes, W. Ruitenbeek, L.A. Sandkuijl, M.F. de Vijlder, P.A. Struyvenberg, J.J. van de Kamp, and J.A. Maassen. 1992. Mutation in mitochondrial tRNA ${ }^{\mathrm{Leu}(U U R)}$ gene in a large pedigree with maternally transmitted type II diabetes mellitus and deafness. Nat. Genet. 1: 368-371.

37. Chiu, K.C., M.A. Province, and M.A. Permutt. 1992. Glucokinase gene is a genetic marker for NIDDM in American blacks. Diabetes. 41:843-849.

38. Permutt, M.A., K.C. Chiu, and T. Yukio. 1992. Glucokinase and NIDDM: a candidate gene that paid off. Diabetes. 41:1367-1372.

39. Noda, K., A. Matsutani, Y. Tanizawa, R. Neuman, T. Kaneko, M.A Permutt, and K. Kaku. 1993. Polymorphic microsatellite repeat markers at the glucokinase gene locus are positively associated with NIDDM in Japanese. Diabetes. 42:1147-1152.

40. Kadowaki, T., H. Sakura, S. Otabe, K. Yasuda, H. Kadowaki, Y. Mori, R. Hagura, Y. Akanuma, and Y. Yazaki. 1995. A subtype of diabetes mellitus associated with a mutation of mitochondrial DNA. Muscle Nerve. 3:S137-S141.

41. 't Hart, L.M., H.H. Lemkes, R.J. Heine, R.P. Stolk, E.J. Feskens, J.J. Jansen, F.E. van der Does, D.E. Grobbee, D. Kromhout, J.M. van den Ouweland, and J.A. Maassen. 1994. Prevalence of maternally inherited diabetes and deafness in diabetic populations in the Netherlands. Diabetologia. 37:1169-1170.

42. Groop, L.C., M. Kankuri, C. Schalin-Jäntti, A. Ekstrand, P. Nikula-Ijas, E. Widen, E. Kuismanen, J. Eriksson, A. Franssila-Kallunki, and C. Saloranta 1993. Association between polymorphism of the glycogen synthase gene and non-insulin-dependent diabetes mellitus. N. Engl. J. Med. 328:10-14.

43. Zouali, H., G. Velho, and P. Froguel. 1993. Polymorphism of the glycogen synthase gene and non-insulin-dependent diabetes mellitus. N. Engl. J. Med. 328:1568.

44. Hager, J., L. Hansen, C. Vaisse, N. Vionnet, A. Philippi, W. Poller, G. Velho, C. Carcassi, L. Contu, C. Julier, and P. Froguel. 1995. A missense mutation in the glucagon receptor gene is associated with non-insulin-dependent diabetes mellitus. Nat. Genet. 9:299-304.

45. DeFronzo, R.A. 1988. Lilly lecture 1987. The triumvirate: beta-cell, muscle, liver. A collusion responsible for NIDDM. Diabetes. 37:667-687.

46. Bogardus, C., S. Lillioja, B.V. Howard, G. Reaven, and D. Mott. 1984. Relationships between insulin secretion, insulin action, and fasting plasma glucose concentration in nondiabetic and noninsulin-dependent diabetic subjects. J. Clin. Invest. 74:1238-1246.

47. Ashcroft, F.M., and S.J.H. Ashcroft. 1992. Mechanism of insulin secretion. In Insulin: Molecular Biology to Pathology. F.M. Ashcroft, and S.J.H Ashcroft, editors. IRL Press at Oxford University Press, Oxford. 97-150.

48. Crockford, P.M., R.J. Harbeck, and R.H. Williams. 1966. Influence of age on intravenous glucose tolerance and serum immunoreactive insulin. Lancet. 1:465-467.

49. Granner, D.K., and R.M. O'Brien. 1992. Molecular physiology and genetics of NIDDM. Diabetes Care. 15:369-395.

50. Brunzell, J.D., R.P. Robertson, R.L. Lerner, W.R. Hazzard, J.W. Ensinck, E.L. Bierman, and D. Porte, Jr. 1976. Relationships between fasting plasma glucose levels and insulin secretion during intravenous glucose tolerance tests. J. Clin. Endocrinol. Metab. 42:222-229.

51. Temple, R.C., C.A. Carrington, S.D. Luzio, D.R. Owens, A.E. Schneider, W.J. Sobey, and C.N. Hales. 1989. Insulin deficiency in non-insulindependent diabetes. Lancet. 1:293-295.

52. Yoshioka, N., T. Kuzuya, A. Matsuda, M. Taniguchi, and Y. Iwamoto. 1988. Serum proinsulin levels at fasting and after oral glucose load in patients with type 2 (non-insulin-dependent) diabetes mellitus. Diabetologia. 31:355-360.

53. McKusick, V.A. 1997. Glycogen storage disease VII. Online Mendelian Inheritance In Man (http://www3.ncbi.nlm.nih.gov:80/htbin-post/Omim/disp$\operatorname{mim} ? 232800)$ 